\title{
Co-infection of disseminated histoplasmosis and tuberculosis in an AIDS patient
}

\author{
Bruno Tomazini ${ }^{a}$, Raquel Bandeira ${ }^{b}$, Thiago Aragãoa, Julio Cesar Andreotti Borges ${ }^{a}$, \\ Rafael Sasdellia, Valéria Pereira Salgado ${ }^{c}$, Fernando Peixoto Ferraz de Campos ${ }^{d}$, \\ Patricia Picciarelli de Lima
}

Tomazini B, Bandeira R, Aragão T, et al. Co-infection of disseminated histoplasmosis and tuberculosis in an AIDS patient. Autopsy Case Rep [Internet]. 2013; 3(3): 49-58 http://dx.doi.org/10.4322/acr.2013.029

\section{ABSTRACT}

\begin{abstract}
Histoplasmosis is a fungal disease caused by the dimorphic fungus Histoplasma capsulatum, recognized as an AIDS-defining illness since the Center for Disease Control's revision criteria in 1985. This infection is reported to be present in $5-20 \%$ of AIDS patients, and in $95 \%$ of the cases it is manifested in its disseminated form. Serum antibodies and/or antigen research can make diagnosis, but the demonstration of the agent by culture or histopathological examination remains the gold standard methods. Co-infections in patients with AIDS are well known; however, reports on disseminated tuberculosis and histoplasmosis are scarce. The authors report the case of a female patient who presented a short-course history of weight loss, fever, and mild respiratory symptoms, with hepatosplenomegaly and lymphadenopathy. Laboratory workup called attention to anemia, altered liver, canalicular enzymes, liver function tests, high titer of lactate dehydrogenase (LDH), and pulmonary nodules on thoracic computed tomography. Incidental finding of yeast forms within the leukocytes during a routine blood cell count highlighted the diagnosis of histoplasmosis. The patient started receiving amphotericin $B$ but succumbed soon after. The authors emphasize the possibility of this co-infection, the diagnosis of severe infection through the finding of yeast forms within peripheral leukocytes, and for the high titer of LDH in aiding the differential diagnosis.
\end{abstract}

Keywords: Histoplasmosis; Tuberculosis; Acquired Immunodeficiency Syndrome; Autopsy.

\section{CASE REPORT}

A 38-year-old Caucasian woman sought medical attention complaining of intermittent fever over the past month. She referred weight loss of $10 \mathrm{~kg}$ during this period, a cough, and daily fever during the last week. She was prescribed clarithromycin for 7 days without relief of the respiratory symptoms or fever defervescence. In the course of her history, right flank and epigastric

\footnotetext{
a Department of Internal Medicine, Hospital das Clínicas, Faculdade de Medicina, Universidade de São Paulo, São Paulo/SP - Brazil.

b Infectious Diseases Institute, Hospital Emílio Ribas, São Paulo/SP - Brazil.

c Clinical Laboratory Service, Hospital Universitário, Universidade de São Paulo, São Paulo/SP - Brazil.

d Department of Internal Medicine, Hospital Universitário, Universidade de São Paulo, São Paulo/SP - Brazil.

e Anatomic Pathology Service, Hospital Universitário, Universidade de São Paulo, São Paulo/SP - Brazil.
}

Copyright $\odot 2013$ Autopsy and Case Reports - This is an Open Access article distributed of terms of the Creative Commons Attribution NonCommercial License (http://creativecommons.org/licenses/by/3.0/) which permits unrestricted non-commercial use, distribution, and reproduction in any médium provided article is properly cited. 
pain was added to the clinical complaints. Her past medical history comprised the diagnosis of asthma. The physical examination on admission showed an ill-looking patient, pale, dehydrated, icteric, and febrile (axillary temperature was $38.9^{\circ} \mathrm{C}$ ). Her pulse was regular at 160 beats per minute; blood pressure was $100 / 60 \mathrm{mmHg}$; respiratory frequency 22 respiratory movements per minute; room air oximetry was $96 \%$; and body mass index was 26.4. Vesicular and crusted lesions were present in the left buccal rhyme, and a serpiginous, paleedged ulcerated lesion was identified in the center of the tongue besides moniliasis of the oral cavity. Lymphadenopathy was palpable in the left cervical chain. Examination of the lungs and heart were unremarkable. The abdomen was slightly distended and diffusely tender; the liver was palpable 4 $\mathrm{cm}$ below the costal margin; and a dull tone was obtained on the percussion of the Traube's space. Bowel sounds were present and normal and no signs of peritoneal irritation were found. Mild lower limbs edema was present bilaterally. The initial laboratory workup is shown in Table 1.

Anti-HIV serology showed positivity for Elisa and Western Blot. Serology for hepatitis B and C resulted as follows: anti-HCV negative, anti-HBsAg negative, anti-HBs positive, anti-HBc positive (IgM negative), anti-HBe positive.

Abdominal computed tomography (CT) showed an enlarged liver with poorly-defined nodular images, hypodense even after iodine contrast injection, measuring $2.5 \times 2.0 \mathrm{~mm}$ in the anterior margin of the left lobe, and another of $8 \mathrm{~mm}$ in the right margin of the right lobe. The spleen was enlarged with multiple hypodense nodular lesions. Adenomegaly with signs of central necrosis/ liquefaction were found along the retroperitoneal, para-aortic, pericaval and iliac chains, as well as in the para-rectal fossa, presacral, and perisplenic regions. A well-delineated mass, measuring $47 \mathrm{~mm}$ $\times 28 \mathrm{~mm}$, was found in the left ischiorectal fossa. The pulmonary CT showed small nodular noncalcified images scattered in both lungs.

The patient was prescribed $600 \mathrm{~mL}$ of packed red blood cells, ceftriaxone, clarithromycin, and sulfamethoxazole/trimethoprim, acyclovir, ivermectin, as well as methylprednisolone. She progressed rapidly to respiratory insufficiency requiring orotracheal intubation and mechanical ventilation. On the second day of the hospital stay norepinephrine was initiated for hemodynamic stabilization. On the third day the laboratory detected yeast forms inside the neutrophils when counting the blood cells during routine examination, bringing the attention for the diagnosis of disseminated histoplasmosis (Figure 1). Amphotericin was started but the patient died later the same day.

Samples of blood culture were positive for Histoplasma capsulatum and Mycobacterium tuberculosis.

Table 1 - Initial laboratory workup

\begin{tabular}{|c|c|c|c|c|c|}
\hline Exam & Result & RV & Exam & Result & RV \\
\hline Hemoglobin & 6.8 & $12.3-15.3 \mathrm{~g} / \mathrm{dL}$ & Creatinine & 0.83 & $0.4-1.3 \mathrm{mg} / \mathrm{dL}$ \\
\hline Hematocrit & 20.9 & $36.0-45.0 \%$ & Potassium & 3.8 & 3.5-5.0 mEq/L \\
\hline Leukocytes & 9.3 & $4.4-11.3 \times 10^{3} / \mathrm{mm}^{3}$ & Sodium & 130 & $136-146 \mathrm{mEq} / \mathrm{L}$ \\
\hline Bands & 16 & $1-5 \%$ & ALT & 584 & 9-36 U/L \\
\hline Segmented & 73 & $45-70 \%$ & AST & 104 & $10-31 \mathrm{U} / \mathrm{L}$ \\
\hline Eosinophils & 1 & $1-4 \%$ & Alkaline $P$ & 813 & $10-100 \mathrm{U} / \mathrm{L}$ \\
\hline Basophils & 0 & $0-2.5 \%$ & yGT & 487 & $2-30 \mathrm{U} / \mathrm{L}$ \\
\hline Lymphocytes & 5 & $18-40 \%$ & Total bilirubin & 3.32 & $0.3-1.2 \mathrm{mg} / \mathrm{dL}$ \\
\hline Monocytes & 2 & $2-9 \%$ & Total protein & 5.3 & $6-8 \mathrm{~g} / \mathrm{dL}$ \\
\hline Platelets & 156 & $150-400 \times 10^{3} / \mathrm{mm}^{3}$ & Albumin & 1.7 & $3-5 \mathrm{~g} / \mathrm{dL}$ \\
\hline INR & 2.06 & 1.0 & LDH & 5598 & $120-246 \mathrm{U} / \mathrm{L}$ \\
\hline Urea & 51 & $5-25 \mathrm{mg} / \mathrm{dL}$ & CRP & 392 & $<5$ mg/L \\
\hline
\end{tabular}

$\mathrm{ALT}=$ alanine aminotransferase; Alkaline $\mathrm{P}=$ alkaline phosphatase; $\mathrm{AST}=$ aspartate aminotransferase; $\mathrm{CRP}=\mathrm{C}$-reactive protein; $\mathrm{\gamma GT}=$ gammaglutamyltransferase; INR = international normalized ratio; LDH = lactic dehydrogenase; RV = reference value. 


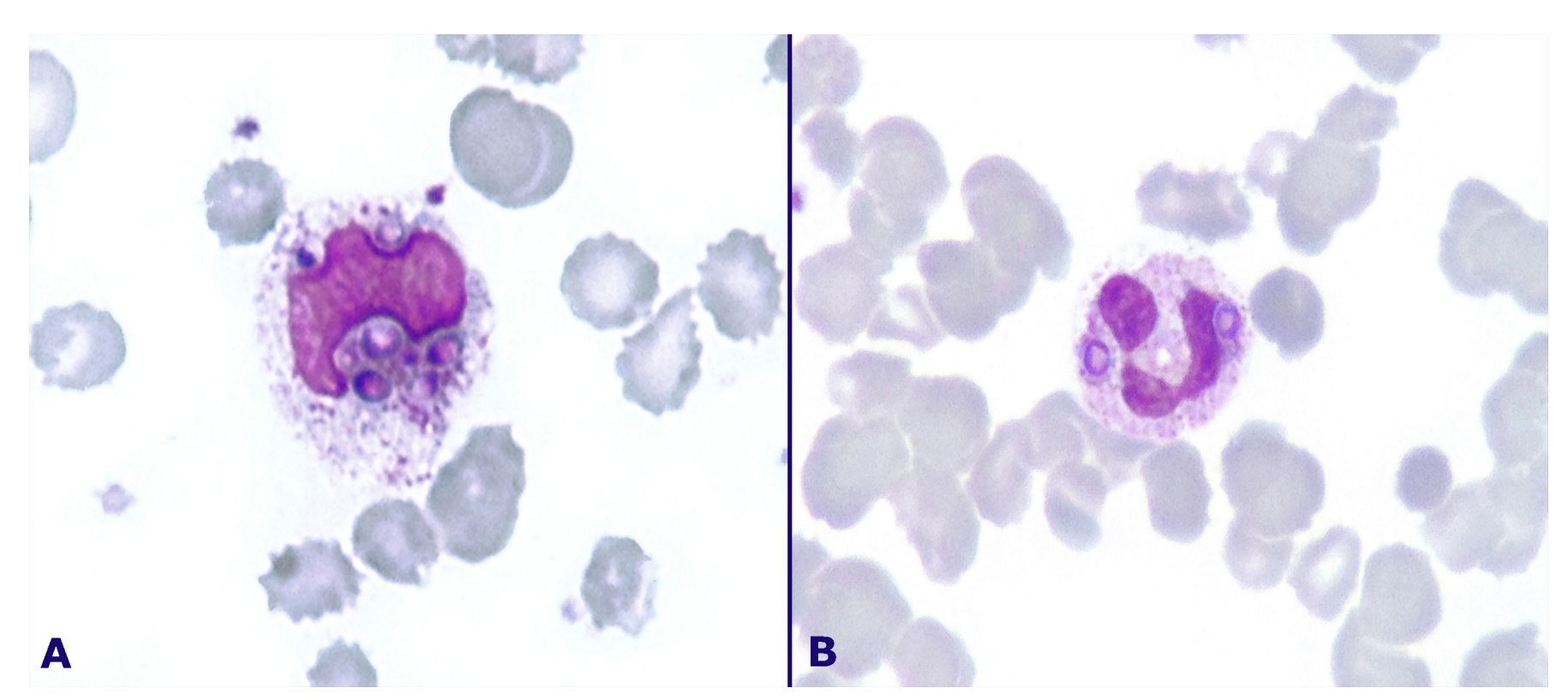

Figure 1 - Photomicrography of the peripheral blood smear showing leukocytes phagocytizing yeast forms of Histoplasma capsulatum (Leishman 100x).

\section{AUTOSPY FINDINGS}

The ectoscopy was unremarkable except for the presence of a hematic-crusted lesion measuring $3 \mathrm{~cm}$ on the left buccal rhyme, which was not represented for microscopy in order to respect and preserve the exposed area.

At the thoracic cavity overture, bilateral serosanguineous pleural effusion was evidenced. The lungs were partially aerated and the bases were congested. The right lung weighed $670 \mathrm{~g}$ (mean reference value [MRV]: $450 \mathrm{~g}$ ) and the left weighed $540 \mathrm{~g}$ (MRV: $375 \mathrm{~g}$ ). On the section surface, multiple whitish nodules measuring up to $0.2 \mathrm{~cm}$ were bilateral and diffusely scattered throughout both lungs (Figure 2A). The surrounding parenchyma was friable and wine-colored.

On microscopic examination, the pulmonary parenchyma showed diffuse ill-defined granulomas; a few of them had rare giant-cells and caseous necrosis. The Ziehl-Neelsen and Gocott staining evidenced the abundant presence of both acidfast bacilli (AFB) and round-form organisms compatible with Histoplasma capsulatum, inside the macrophages (Figure 3). Some areas also showed alveolar spaces filled in by suppurative infiltrate surrounded by areas of organizing pneumonia as well as pulmonary edema. Gross examination of the pericardium, heart, and valve apparatus was normal.
At the opening of the abdominal cavity, 400 $\mathrm{mL}$ of a yellow citrine ascites were present. The spleen was enlarged, weighing $631 \mathrm{~g}$ (RV: $112 \mathrm{~g}$ ), showing a softened consistency. Multiple yellowish nodules measuring up to $1.0 \mathrm{~cm}$ were diffusely distributed throughout the parenchyma (Figure 2B).

On microscopy, white pulp depletion was evident. Multiple micro infarctions and abscesses were present, as well as ill-defined granulomas, which were crammed by yeast forms and some AFB (Figure 4).

The liver was congested and weighed $2670 \mathrm{~g}$ (RV range: 1320-1740 g). On microscopy, centrilobular hepatic necrosis and marked macrovesicular steatosis were observed. Additionally, multiple necrotic hepatocyte foci were present in conjunction with countless ill-defined granulomas distributed in the portal spaces and within the hepatic lobules. Ziehl-Neelsen and Grocott staining showed round organisms compatible with Histoplasma capsulatum as well as AFB inside the macrophages (Figure 5).

Gastric mucosa showed signs of stress bleeding, and in the duodenum wine-colored nodules of $0.2 \mathrm{~cm}$ were present, represented by small foci of submucosal hemorrhage on microscopy. In some of these areas, yeast forms were depicted, by Grocott stain, without eliciting an intense inflammatory response. The kidneys were normal in size (both weighed $478 \mathrm{~g}$, RV range: $240-$ 


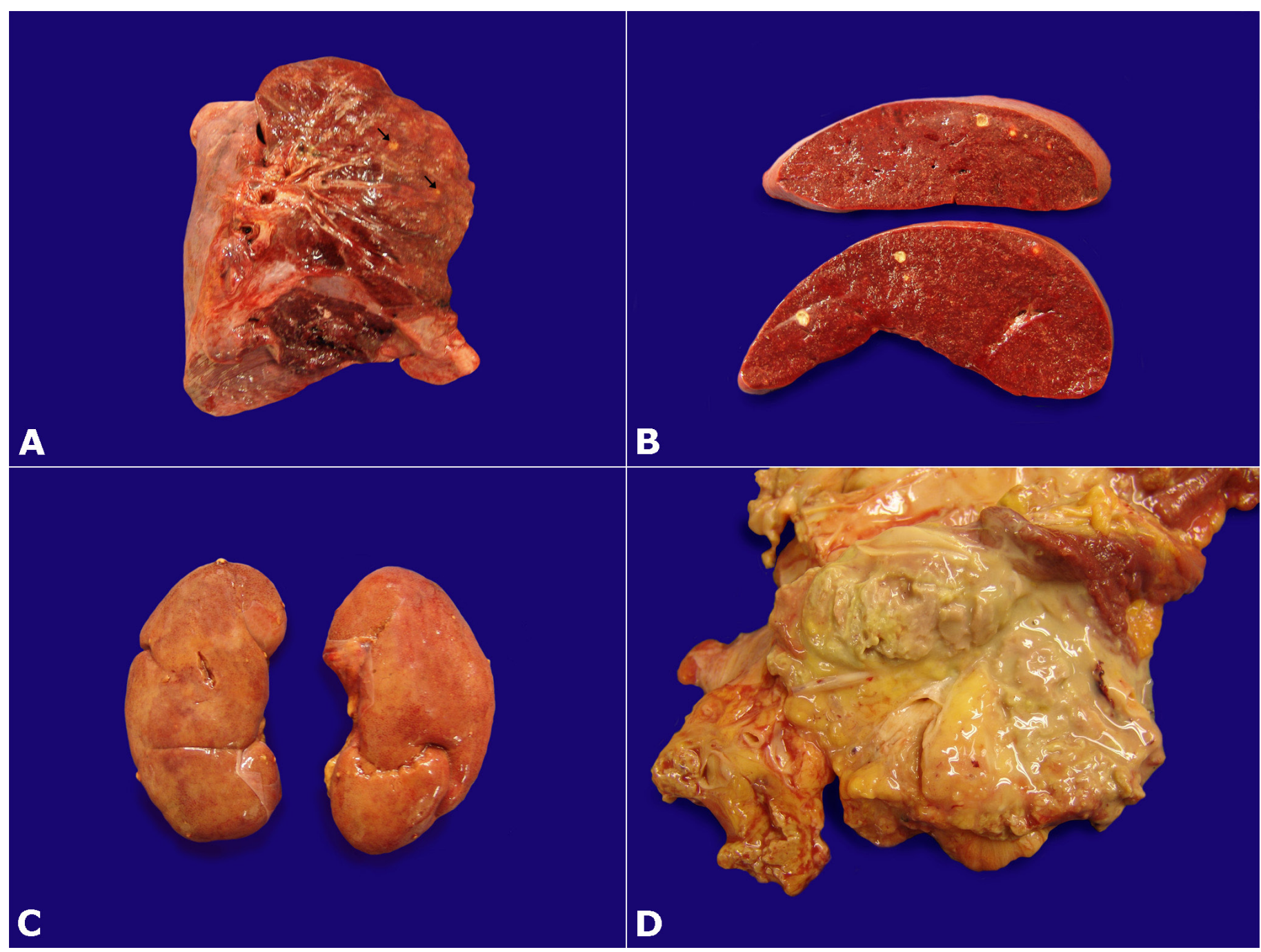

Figure 2 - Gross examination of: A - Lung parenchyma with nodules (arrows); B - Splenic cross-sections showing yellowish nodules; C - Both kidneys showing small yellowish nodules protruding trough the capsule; D - Gross view of the cross section of the aortoiliac lymph node conglomerate, showing abundant purulent secretion.

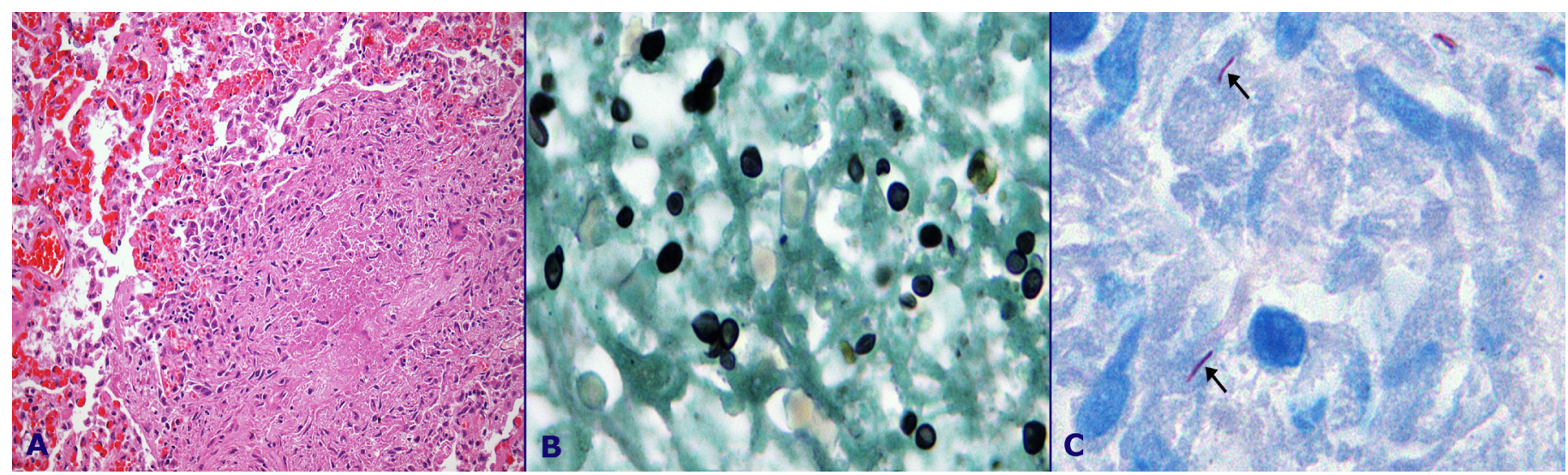

Figure 3 - Photomicrography of the lung. A - Note an ill-defined granuloma with central caseous necrosis, and a giant cell (HE 20x); B - Round-form organisms compatible with Histoplasma capsulatum, (Grocott 40x); C - Shows the presence of acid-fast bacilli (AFB) (arrows) (Ziehl-Neelsen 100x).

$350 \mathrm{~g})$ and presented, bilaterally, yellowish nodules measuring up to $0.5 \mathrm{~cm}$. Some of them were seen at the cortical surface, draining pus-like material when digitally compressed (Figure 3C). On microscopy, these nodules represented abscesses with round- form organisms compatible with Histoplasma capsulatum as well as AFB inside the macrophages, stained by Grocott and Ziehl-Neelsen, respectively. Marked acute tubular necrosis was also present (Figure 6). 


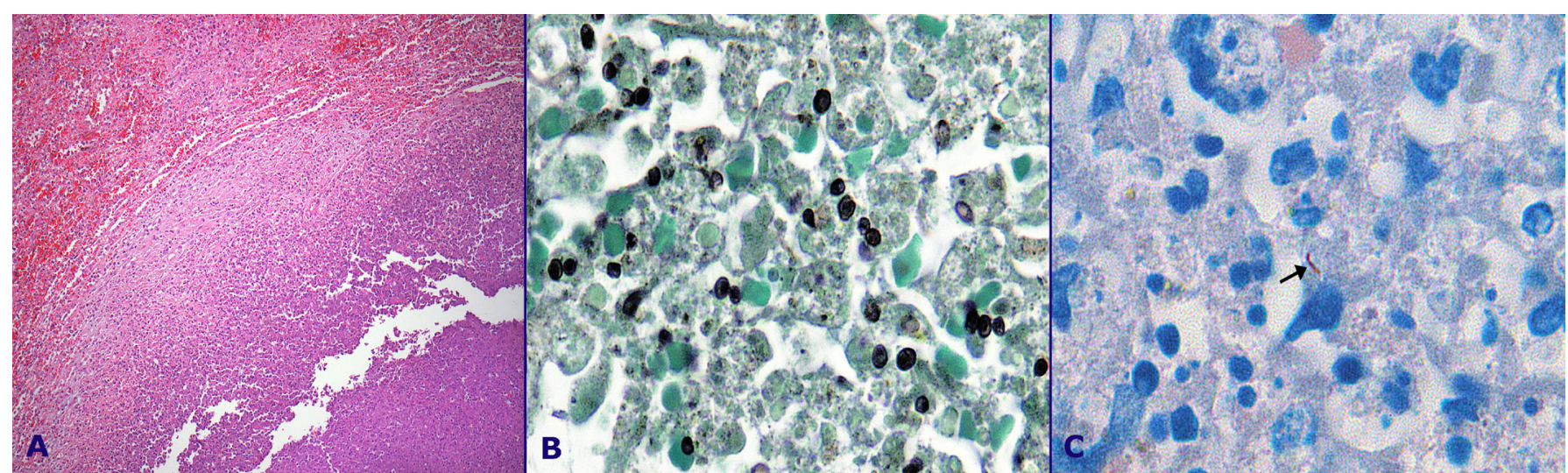

Figure 4-Photomicrography of the spleen. A - Splenic abscess margin, (HE 10x); B - Round-form organisms compatible with Histoplasma capsulatum, (Grocott 40x); C - The presence of AFB (arrow), (Ziehl-Neelsen 100x).

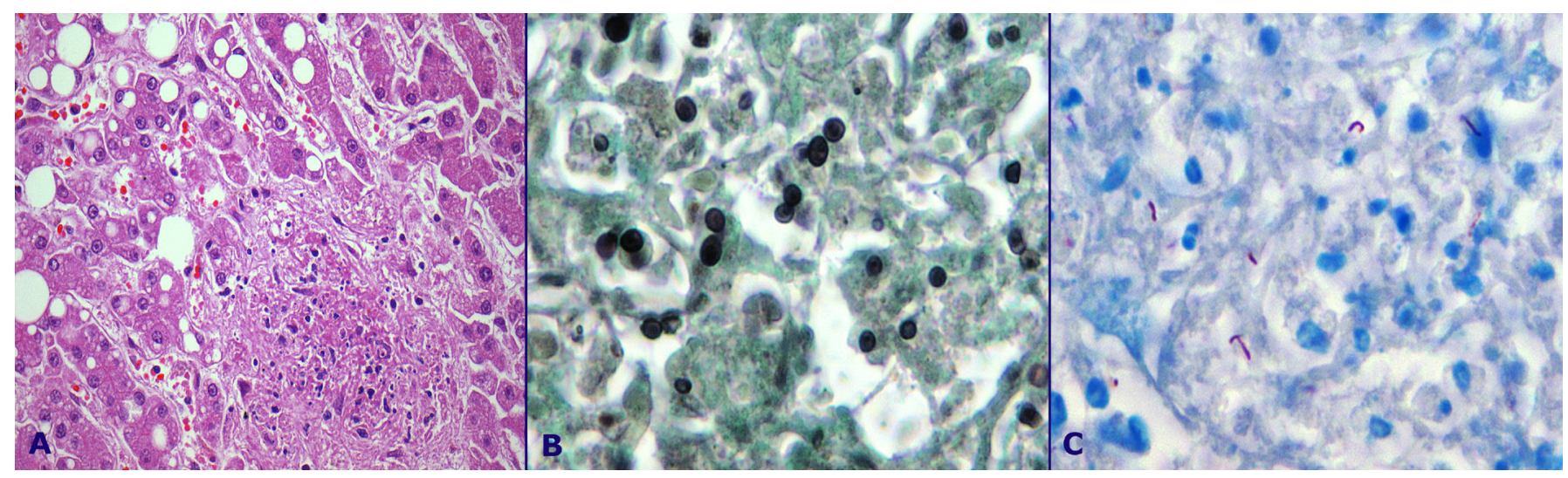

Figure 5-Photomicrography of the liver. A - Note an ill-defined granuloma and macrovesicular steatosis (HE 20x); B - Round-form organisms compatible with Histoplasma capsulatum, (Grocott 40X); C - The presence of AFB (Ziehl-Neelsen 100x).

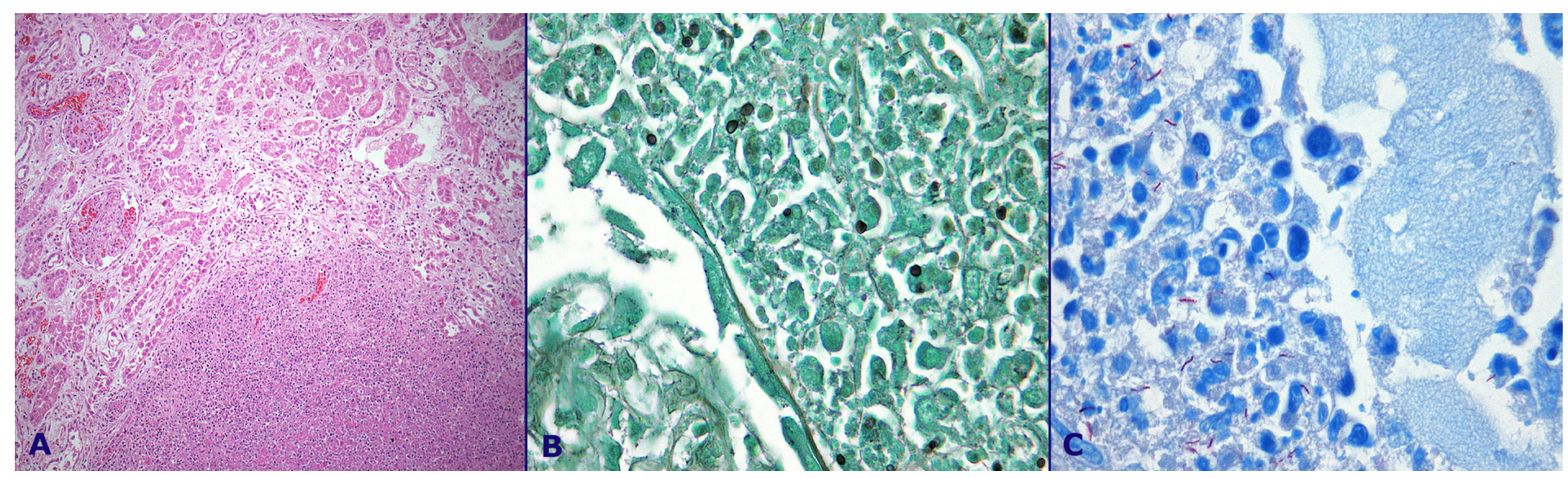

Figure 6 - Photomicrography of the kidney. A - Intra renal abscess (HE 20x); B - Round-form organisms compatible with Histoplasma capsulatum, (Grocott 100x); C - The presence of AFB (Ziehl-Neelsen 100x).

Extensive lymphadenopathy was observed along the para-aortic, peri-iliac, submandibular and cervical chains. The lymph nodes measured up to 2 $\mathrm{cm}$ and at the section surface did not show necrosis, but on microscopy necrosis and granulomas sketches were present. A lymph node conglomerate, measuring $10 \times 10 \times 7 \mathrm{~cm}$ was present in the right aortoiliac region, adhering to the iliopsoas muscle, which at the cut section exhibited a huge amount of purulent secretion drainage (Figure 3D).

On microscopy, the affected lymph nodes showed the replacement of normal nodal architecture by a suppurative process and ill-defined granulomas that were overcrowded by AFB and round-form organisms compatible with Histoplasma 
capsulatum depicted by the Ziehl-Neelsen and Grocott staining, respectively (Figure 7).

The bone marrow was hypercellular at the expense of the granulocytic lineage, showing scattered necrotic foci with sketches of granuloma. Ziehl-Neelsen and Grocott staining evidenced AFB and round-form organisms compatible with Histoplasma capsulatum, respectively (Figure 8).

The microscopic examination of the adrenal gland showed necrotic foci inside which round-form organisms compatible with Histoplasma capsulatum were found (Figure 9).

The microscopic examination of the tongue evidenced intense inflammatory cell infiltration and rupture of the continuity solution, and the presence of abundant round-form organisms compatible with Histoplasma capsulatum in the corium (Figure 10).

The remaining organs did not show abnormalities.

\section{DISCUSSION}

Histoplasmosis is a fungal disease, first described by Samuel Darling in 1905 in Panama, ${ }^{1}$ who identified this pathogen in a patient presumed to have died of tuberculosis. Although distributed in the temperate climate areas worldwide, it is endemically found in river valleys from North and Central America, parts of Europe, Africa, East Asia, Australia, and Brazil. ${ }^{2,3}$

The infection usually begins in the lungs ${ }^{4}$ by inhaling airborne, microscopic fungal spores of the dimorphic fungus Histoplasma capsulatum, which remains in a mycelial form at ambient temperatures and grows as yeast at body temperature in mammals. Once in the alveoli, inhaled micronidia are englobed by alveolar macrophages where they replicate and spread to regional lymph nodes, and thereafter throughout the reticuloendotelial system. Oral Histoplasma capsulatum infection has been reported in association with HIV infection. Hence oropharyngeal mucosa should also be considered

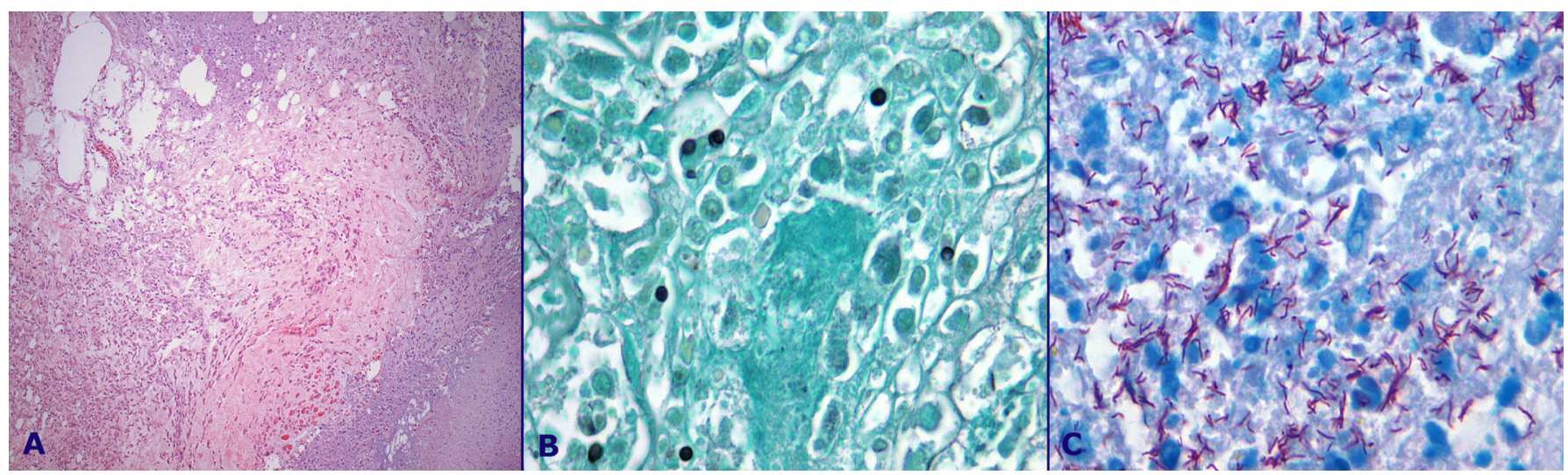

Figure 7 - Photomicrography of the lymph node. A - III-defined granuloma with central necrosis, (HE 20x); B - Round-form organisms compatible with Histoplasma capsulatum, (Grocott 40x); C - The presence of AFB (Ziehl-Neelsen 100x).

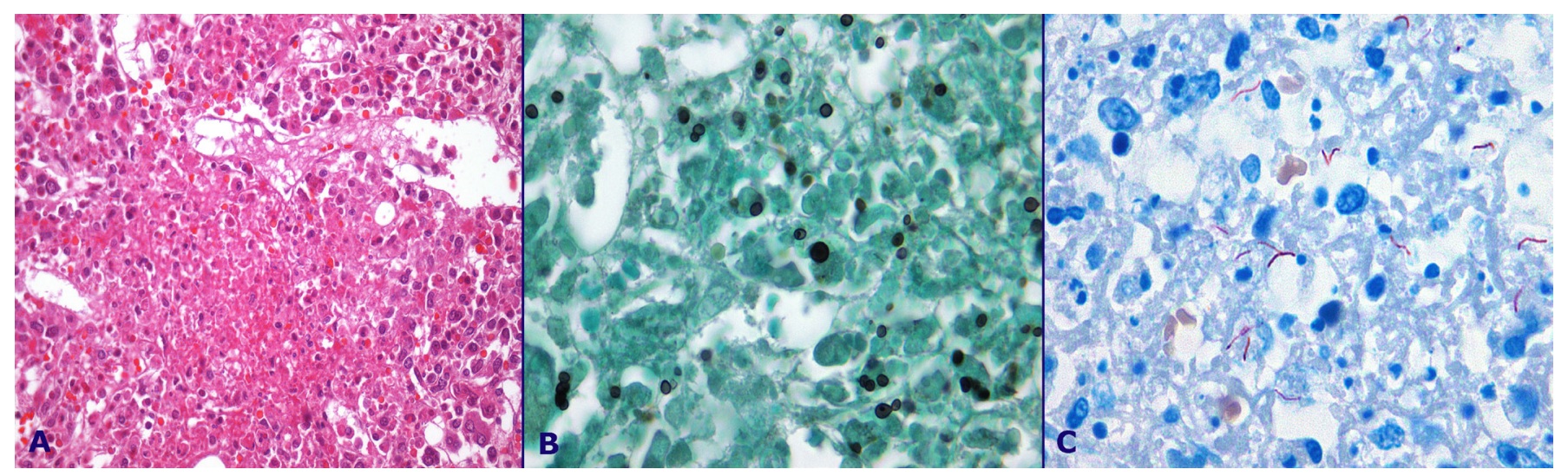

Figure 8 - Photomicrography of the bone marrow. A - Hypercellularity of the bone marrow and an illdefined granuloma with central necrosis. (HE 40x); B - Round-form organisms compatible with Histoplasma capsulatum (Grocott 40x); C - The presence of AFB (Ziehl-Neelsen 100x). 


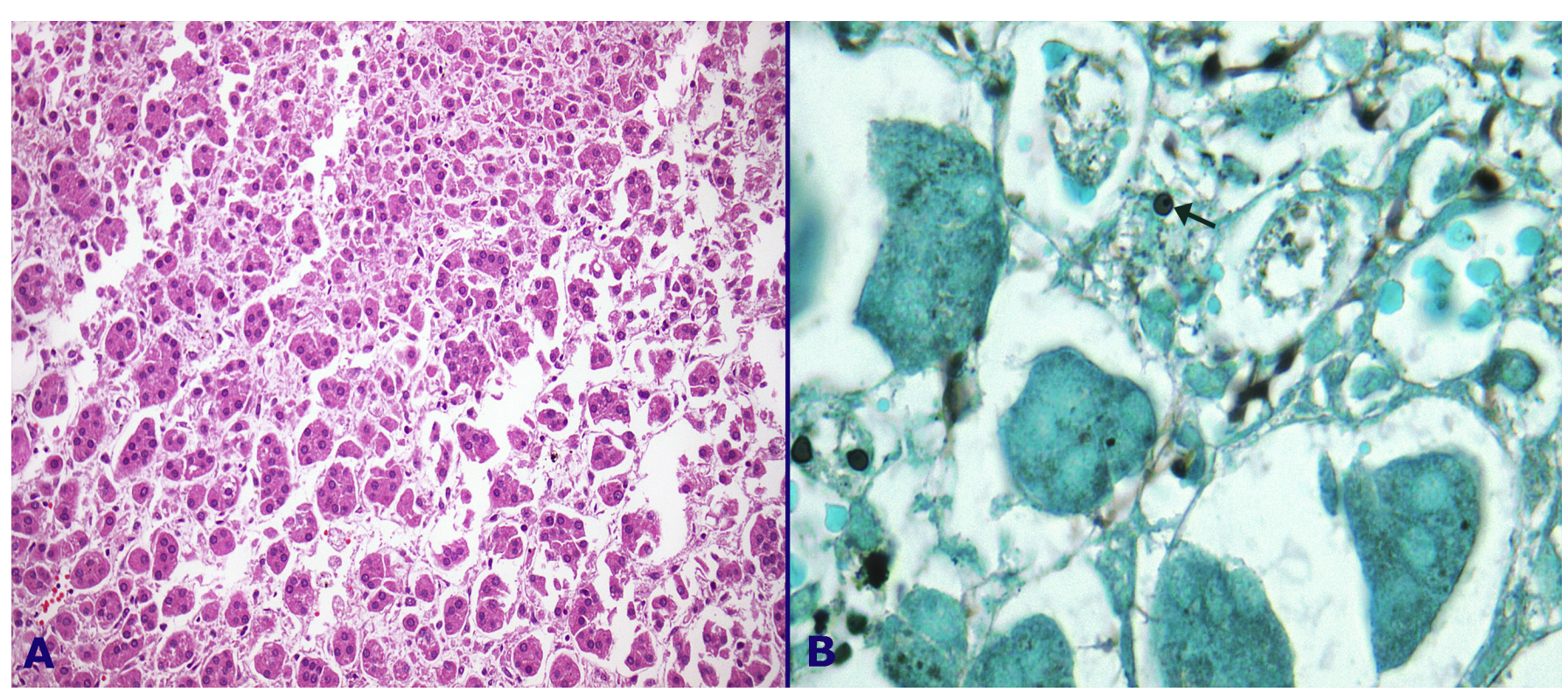

Figure 9 - Photomicrography of the adrenal gland. A - Edema and acute inflammatory cell infiltration of the zona reticularis. (HE 20X); B - Round-form organisms (arrow) compatible with Histoplasma capsulatum, within the zona fasciculata (Grocott 100x).

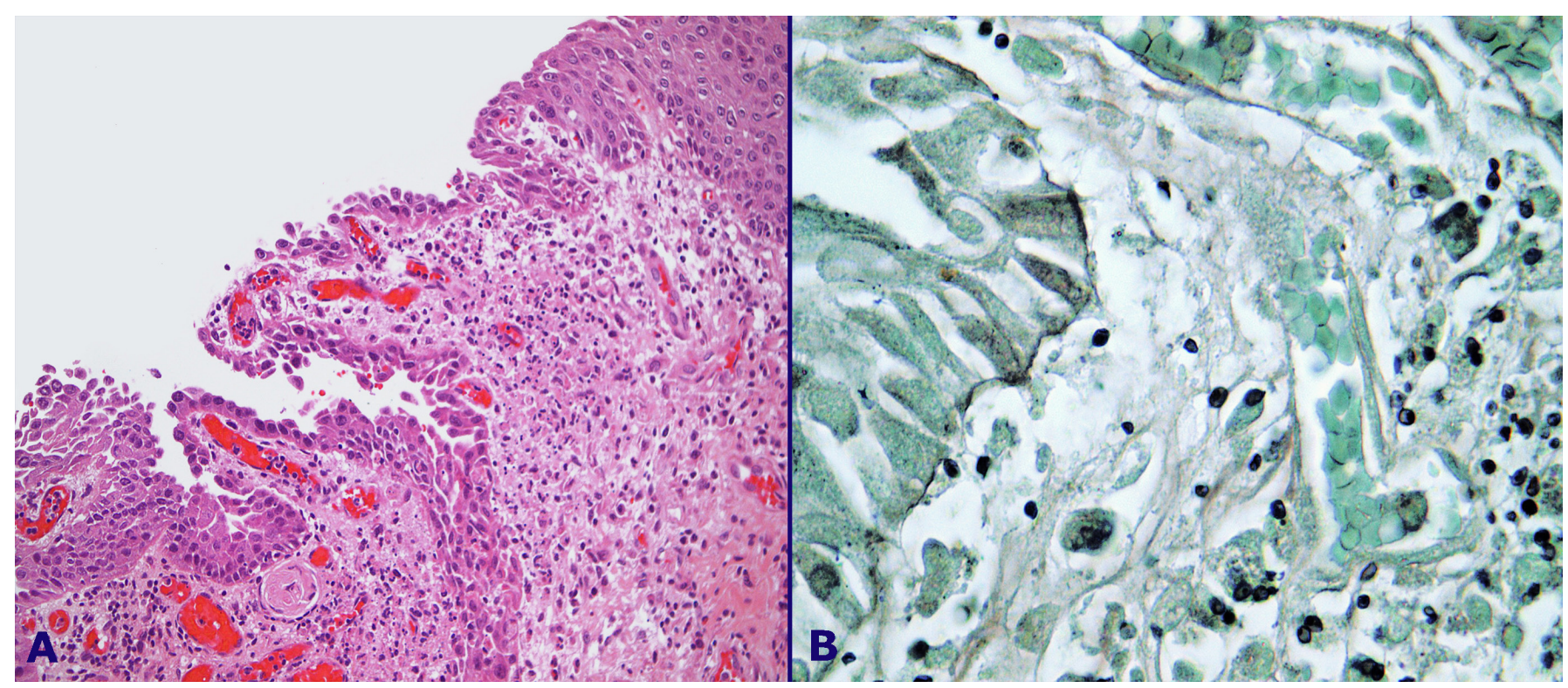

Figure 10 - Photomicrography of the tongue. A - Inflammatory cell infiltration of the corium and a small continuity solution of the papilla, (HE 20x); B - Note round-form organisms compatible with Histoplasma capsulatum, (Grocott 100x).

another "port of entry" of this fungal infection. Infected macrophages and sensitized T cells enlist monocytes through cytokines induction, to fight the organism, forming a granuloma. When this T-cell mediated immune response fails, a progressive spread of infection to other organs ensues. ${ }^{2,5}$ Although mucocutaneous lesions usually indicate disseminated disease, occasionally patients may present seemingly isolated mucocutaneous lesions with no apparent active disease elsewhere. ${ }^{6,7}$ The patient of this report presented a lesion in the median sulcus of the tongue, which on microscopy, showed to be fully infiltrated by inflammatory cells and yeast forms. In this case, it is difficult to state the initial inoculum.

The clinical manifestations vary with the intensity of conidia exposure and host immunity. In healthy or immunocompetent individuals, the infection courses asymptomatic, or mildly symptomatic and self-limited, but can be potentially lethal in immunosuppressed patients, when even small inoculum can cause severe pulmonary infection or disseminated histoplasmosis $(\mathrm{DH}){ }^{2}$ The latter has been described amongst patients with diabetes mellitus; hematologic malignancies; 
transplant recipients, carriers of the HIV virus infection, and those under tuberculosis treatment or under corticotherapy. ${ }^{5,8,9}$

Histoplasmosis is present in $5-20 \%$ of AIDS patients, and occurs in its disseminated form in about $95 \%$ of cases when the CD4 determination is below 150 cells $/ \mathrm{mm}^{3,9-12}$ The development of histoplasmosis during the deep state of immunosuppression of AIDS, in an endemic area, may be due to primary infection, reinfection, or reactivation. ${ }^{12}$ Clinically disseminated histoplasmosis manifests as fever, malaise, diarrhea, anorexia, and weightloss. Physical examination usually displays hepatosplenomegaly and lymph adenopathy. Mucosa and skin lesions also may be present in some patients. ${ }^{13-15}$ Diarrhea, in these cases, may be due to Salmonella, Shigella or Giardia co-infection. , $^{916}$ Progressive disseminated histoplasmosis is a relentlessly life-threatening infection characterized by multiorgan involvement, the outcome of which will result in coagulopathy, shock, respiratory failure, hepatic failure, and renal insufficiency. ${ }^{13}$

Laboratory findings are non-specificand show anemia, thrombocytopenia, and increased levels of alkaline phosphatase, ferritin, C-reactive protein, and erythrocyte sedimentation rate. Leukopenia may be found in $50 \%$ of patients. Elevated lactic dehydrogenase (LDH) levels are highly prevalent in patients with AIDS and disseminated histoplasmosis, reaching $84.2 \%$ in some Brazilian series. ${ }^{15,17} \mathrm{LDH}$ determination greater than 600 $\mathrm{U} / \mathrm{L}$ shows a high specificity for the diagnosis of histoplasmosis in patients with AIDS when compared with Pneumocystis jiroveci pneumonia ${ }^{18}$ and other opportunistic infections presenting fever and pulmonary infiltrates. ${ }^{19}$ Moreover, this biochemical marker is an isolated factor of poor prognosis in the course of the disease. ${ }^{20}$

Some reports have been showing the diagnosis of histoplasmosis through the analysis of peripheral blood smears. This finding is usually related to severe cases. Round-form organisms of 3-4 $\mu \mathrm{m}$, with basophilic cytoplasm and a false impression of a peripheral capsule, are depicted inside the leukocytes. ${ }^{21-23}$. This diagnostic method has a limited use because of its low sensitivity, which has been shown to be $12 \% .^{22}$

Diagnosis can be established by antibody assays through immunodiffusion or complement fixation tests, which show specificity around $80 \%$. It seems that the usefulness of these tests is controversial in AIDS patients since Mandel et al. ${ }^{8}$ reported three cases that had negative results. The research for polysaccharide antigen by an enzyme immunoassay in urine, serum, and other body fluids may be used for the rapid diagnosis of disseminate histoplasmosis. The cytology and culture of bronchial aspirates and cultures of blood, bone marrow, or biopsied tissues, together with the histopathological examination, represent the definitive diagnosis. Blood culture positivity has been reported in $54 \%$ of cases, bone marrow culture in $56 \%$, while bone marrow biopsy yielded the diagnosis in $69 \%$ of the patients. ${ }^{9}$ The predictive value of these diagnostic methods will vary with host factors, such as the inflammatory response and the severity of infection. ${ }^{2,24}$

Since 1985, $\mathrm{DH}$ has been considered an AIDS-defining illness, ${ }^{25}$ and it is not uncommon to find it concurrently with other opportunistic infection, indicating the need for a careful search for co-infections. In a series of 104 cases of $\mathrm{DH}$, Gutierrez et al. ${ }^{14}$ found 27 patients co-infected $(25.9 \%)$ and among them, tuberculosis was present. Johnson et al. ${ }^{9}$ reported a series of 48 cases of $\mathrm{DH}$ in AIDS patients, where coinfection was found in 8 cases (16\%). Two patients had Pneumocystis jirovecii pneumonia, two had Mycobacterium avium complex, and one from each had cryptococcal pneumonia, tuberculosis, pulmonary nocardiosis, or paracoccidioidomycosis. The association of disseminated histoplasmosis and disseminated tuberculosis is scarcely described in the literature. ${ }^{4,26-28}$ Furthermore, a few cases of histoplasmosis were reported to be misdiagnosed as tuberculosis in Europe and Malaysia. ${ }^{29,30}$ Clinical features do not allow the identification of this coinfection in AIDS patients; nevertheless, they have important treatment and prognosis implications. Both infections are implicated in pulmonary, lymph node, and miliary involvement, and share many similar signs and symptoms. The clinical, laboratory, and radiological abnormalities often overlap, making the specific diagnosis a tough task.

In a retrospective study of 14 patients with these three co-infections, the clinical manifestations most often found were: weight loss $(85.7 \%)$, asthenia $(78.5 \%)$, and fever $(64.2 \%)$. The diagnosis of histoplasmosis was made primarily by histopathology and tuberculosis by direct microscopic examination. ${ }^{31}$

Facing the suspicion of co-infection, tuberculosis should be initially considered, given its 
higher prevalence and the importance of preventing it spreading. The diagnosis of histoplasmosis usually arises later, when the specific treatment for tuberculosis did not succeed. ${ }^{31}$

The patient of this report presented a shortcourse disease with non-specific symptoms. She denied a previous diagnosis of HIV infection, but the weight loss, the presence of oral moniliasis, and tomographic signs indicating tuberculosis early raised the suspicion of HIV infection, which was later confirmed by serologic tests. The presence of anemia and lymphopenia was attributed to the diagnosis of AIDS, and the alterations of the liver and canalicular enzymes, as well as hypoalbuminemia, were considered as taking part of the miliary tuberculosis. The high titers of LDH remained unexplained until the incidental discovery of yeast structures within the leukocytes. This information took the medical staff by surprise, since the respiratory insufficiency was being attributed to a probable Pneumocystis jirovecii co-infection, due to its higher frequency. High titers of LDH and the presence of yeast forms inside the leukocytes, in these cases, are strongly related to poor prognosis.

\section{CONCLUSION}

We have learned through this case, that whenever facing a severe case of a patient with the diagnosis of AIDS, we should always be on lookout for co-infections. Moreover, a high determination of serum LDH should always raise suspicion for the diagnosis of $\mathrm{DH}$. If the clinical signs support the diagnosis of this fungal infection, then depending on the severity of the illness empiric treatment should be started to give the patient an optimum chance for survival.

\section{ACKNOWLEDGEMENTS}

The authors are thankful for Erica Chimara $\mathrm{PhD}$ and Dulce Helena de Matos PhD from the Instituto Adolfo Lutz of São Paulo / SP - Brazil, for the identification of the pathogens and Thiago Rodrigo Noronha pharmaceutic of the Clinical Laboratory of Hospital Universitário - Universidade de São Paulo - São Paulo/SP - Brazil, who kindly provided the pictures from peripheral blood.

\section{REFERENCES}

1. Darling ST. A protozoan general infection producing pseudotubercles in the lungs and focal necroses in the liver, spleen, and lymph nodes. JAMA. 1906;46:1283-5. http://dx.doi.org/10.1001/jama.1906.62510440037003

2. Kauffman CA. Histoplasmosis. Clin Chest Med. 2009;30:217-25. PMid:19375629. http://dx.doi.org/10.1016/j. ccm.2009.02.002

3. Ajello L. Distribution of histoplasma capsulatum in the United States. In: Ajello L, Chick W, Furculow MF, editors. Histoplasmosis. Springfield: Charles C. Thomas; 1971. p. 103-22. PMid:4325151.

4. Wheat LJ, Connolly-Stringfield PA, Baker RL, et al. Disseminated histoplasmosis In the acquired immune deficiency syndrome: clinical findings, diagnosis and treatment, and review of the literature. Medicine. 1990;69:36174. http://dx.doi.org/10.1097/00005792-199011000-00004

5. Subramanian S, Abraham OC, Rupali P, et al. Disseminated histoplasmosis. JAPI. 2005;53:185-9. PMid:15926599.

6. Boden RA, Conn D. Disseminated histoplasmosis with an oral lesion. Report of a case. Oral Surg Oral Med Oral Pathol. 1967;23:549-56. http://dx.doi.org/10.1016/00304220(67)90551-8

7. Greenspan HCG, MacPhal LA, SehiØdt M. Oral histoplasma capsulatum infection in association with HIV infection: a case report. J Oral Pathol Med. 1992;21:85-9. http://dx.doi. org/10.1111/j.1600-0714.1992.tb00985.x

8. Mandel W, Goldbert DM, Neu HC. Histoplasmosis in patients with the acquired immunodeficiency syndrome. Am J Med. 1986;81:974-8. http://dx.doi.org/10.1016/00029343(86)90390-6

9. Johnson PC, Khardori N, Najjar AF, et al. Progressive disseminated histoplasmosis in patients with acquired immunodeficiency syndrome. Am J Med. 1988;85:1552-8. http://dx.doi.org/10.1016/S0002-9343(88)80334-6

10. Suh KN, Anekthansnon T, Marius PR: Gastrointestinal histoplasmosis in patients with AIDS: case report and review. Clin Infect Dis. 2001,32:482-91. PMid:11170958. http:// dx.doi.org/10.1086/318485

11. McKinsey DS, Spiegel RA, Hutwanger L, et al. Prospective study of histoplasmosis in patients infected with human immunodeficency virus: incidence, risk factors, and pathophysiology. Clin Infect Dis. 1997;24:1195-203. http:// dx.doi.org/10.1086/513653

12. Wheat LJ, Kaufman CA. Histoplasmosis. Infect Dis Clin North Am. 2003;17:1-19. http://dx.doi.org/10.1016/S08915520(02)00039-9 
13. Kauffman CA. Histoplasmosis: a clinical and laboratory update. Clin Microbiol Rev. 2007;20:115-32 PMid:17223625 PMCid:PMC1797635. http://dx.doi.org/10.1128/CMR.00027-06

14. Gutierrez ME, Canton A, Sosa N, et al. Disseminated histoplasmosis in patients with AIDS in Panama: a review of 104 cases. Clin Infect Dis. 2005;40:1199-202. PMid:15791523. http://dx.doi.org/10.1086/428842

15. Pontes LB, Leitão TMJS, Lima GG, et al. Características clínico-evolutivas de 134 pacientes com histoplasmose disseminada associada a SIDA no estado do Ceará. Rev Soc Bras Med Trop. 2010;43:27-31. Portuguese. PMid:20305964. http://dx.doi.org/10.1590/S0037-86822010000100007

16. Wheat LJ, Rubin RH, Harris NL, et al. Systemic salmonelosis in patients with disseminated histoplasmosis. Arch Intern Med. 1987;147:561-4. http://dx.doi.org/10.1001/ archinte.1987.00370030165032

17. Mora DJ. Disseminated histoplasmosis in acquired Immunodeficiency syndrome patients in Uberaba, MG, Brazil. Mycoses. 2008,51:136-40. PMid:18254750. http:// dx.doi.org/10.1111/j.1439-0507.2007.01459.x

18. Butt AA, Michaels S, Greer D, Clark R, Kissinger P, Martin DH. Serum LDH level as a clue to the diagnosis of histoplasmosis. AIDS Read. 2002;12:317-21. PMid:12161854.

19. Corcoran GR, Abdely H, Flanders CD, Geimer J, Patterson FT. Markedly elevated serum lactate dehydrogenase levels are a clue to the diagnosis of disseminated histoplasmosis in patients with AIDS. Clin Infect Dis. 1997;24:942-4. http:// dx.doi.org/10.1093/clinids/24.5.942

20. Couppié P, Sobesky M, Aznar C, et al. Histoplasmosis and acquired immunodeficiency syndrome: a study of prognostic factors. Clin Infect Dis. 2004;38:134-8. PMid:14679459. http://dx.doi.org/10.1086/379770

21. Singh NK, Nagendra S. Histoplasma capsulatum in peripheral blood smear. BMJ Case Reports. 2009. Available from: http://casereports.bmj.com/content/2009/bcr.05.2009.1877. full?sid=ba402f77-198a-44c5-8d26-c1604bad68d1 doi:10.1136/bcr.05.2009.1877 http://dx.doi.org/10.1136/ bcr.05.2009.1877

\section{Conflict of interest: None}

Submitted on: $30^{\text {th }}$ June 2013

Accepted on: $14^{\text {th }}$ September 2013

Correspondence: Divisão de Clínica Médica Hospital Universitário da USP

Av. Prof. Lineu Prestes, 2565 - Cidade Universitária - São Paulo/SP - Brazil

CEP: $05508-000$ - Phone: +55 (11) 3091-9275

E-mail: fpfcampos@gmail.com
22. Casanova-Cardiel LJ, Ruiz-Ordaz I. Histoplasma capsulatum in the peripheral blood of patients with AIDS. Report of 4 cases with an increase of lactate dehydrogenase. Rev Invest Clin. 1993;45:67-70. PMid:8484068.

23. Kennedy GA, Curnow JL, Gooch J, et al. Histoplasma capsulatum in peripheral blood smears. $\mathrm{Br} \mathrm{J}$ Haematol. 2002;116:503. http://dx.doi.org/10.1046/j.00071048.2001.03276.x

24. McKinsey DS, McKinsey JP. Pulmonary histoplasmosis. Semin Respir Crit Care Med. 2011;32:735-44. PMid:22167401. http://dx.doi.org/10.1055/s-0031-1295721

25. Center for Disease Control (US). Revision of the case definition of acquired immune deficiency syndrome for national reporting - United States. MMWR. 1985;34:373-5. PMid:2989677.

26. Jeong HW, Sohn JW, Kim MJ, et al. Disseminated histoplasmosis and tuberculosis in a patient with HIV infection. Yonsei Med J. 2007;48:531-4. http://dx.doi.org/10.3349/ ymj.2007.48.3.531

27. Pinotti AFF, Severo LC, Randon M, Rigatto M, Haase HB. Disseminated histoplasmosis associated with tuberculosis in immunosuppressed patients. Rev Ass Med Brasil. 1983;29:6870.

28. Rezende RE, Brunaldi MO, Girão MS. Esophageal histoplasmosis associated with disseminated tuberculosis in acquired immunodeficiency syndrome. J Trop Med Hyg. 2009,80:347-50.

29. Pometta R, Rovato C, Vivani MA, et al. Chronic pulmonary histoplasmosis in a patient with a recent history of tuberculosis and persistent round lung lesions. Eur J Clin Microbiol Infect Dis.1999;18:229-31. http://dx.doi.org/10.1007/s100960050267

30. Chan KS, Looi LM, Chan SP. Disseminated histoplasmosis mimicking military tuberculosis: a case report. Malays $\mathrm{J}$ Pathol. 1993;15:155-8. PMid:8065179.

31. Agudelo CA, Restrepo CA, Molina DA, et al. Tuberculosis and histoplasmosis co-infection in AIDS patients. Am J Trop Med Hyg. 2012;87:1094-8. PMid:23128292. http://dx.doi. org/10.4269/ajtmh.2012.12-0292 